\title{
Research on the Foreign Students Education of Shandong Province under the Internationalization Background
}

\author{
Xianghua Wang ${ }^{1} \&$ Wenxiu $\mathrm{Li}^{1}$ \\ ${ }^{1}$ College of Education, Shandong Normal University, Jinan, China \\ Correspondence: Xianghua Wang, Professor of College of Education, Shandong Normal University, Jinan, \\ Shandong, 250014, China. Tel: 86-531-8618-2628. E-mail: xhwang@126.com
}

Received: May 8, 2016

Accepted: June 16, $2016 \quad$ Online Published: October 26, 2016

doi:10.5539/ies.v9n11p121

URL: http://dx.doi.org/10.5539/ies.v9n11p121

This work was financially supported by the Foundation for Outstanding Young Scientist in Shandong Province (BS2012SF029) and Excellent Young Scholars Research Fund of Shandong Normal University.

\begin{abstract}
The foreign students' education has a great influence on the internationalization of higher education and the reputation of university. Since the 21 st century, the foreign students' education has developed rapidly and has been extending continuously in Shandong Province. However, a series of problems still exist, such as the imperfect of the specialty structure and curriculum, which have impeded the sustainable development of the foreign students' education. This article would carry on the discussion about the current situation and existing problems of the foreign students education in Shandong Province from the following aspects: the scale, the construction of specialized curriculum system and the management, etc. And based on that, we put forward feasible countermeasures, in order to offer certain reference to the development of foreign students' education.
\end{abstract}

Keywords: internationalization, Shandong Province, the foreign students' education

\section{Introduction}

Higher education internationalization is not only a necessary demand of social development, but also an important embodiment of the essential characteristics of higher education. Both the developed and developing countries have regarded internationalization as one of the important strategies of their countries' development of higher education at present. Higher education internationalization has extensive contents which mainly involve the international educational idea, international courses, international exchange of faculties, international academic exchange and cooperative research, etc. Foreign students' education is an important part of higher education internationalization, its quantity and quality has become a significant symbol of the university internationalization. Meanwhile, to energetically develop it has important strategic meaning to enhance the international competitiveness of foreign students market and promote the international construction of colleges and universities.

The domestic and foreign scholars have conducted a series of studies on foreign students' education. Basing on the status of foreign students in the United States since 1980s, Shu (2012) discussed the factors for the formation and the rise of the world educational market for foreign students, and pointed out that it was the world-leading comprehensive national strength that made American stayed at the dominant state in the world educational market for foreign students (Shu, 2012). Roga, Lapiņa, and Müürsepp (2015) found that academic quality, academic reputation and international students and staff were important factors affecting students to choose high education institutions, thereby they suggested further improvements such as the language of instruction, teaching and learning environment, study programs, etc. (Roga et al., 2015); after analyzing and summarizing the outstanding problems existing in the foreign students education in China, Li (2012), Xi (2013), Yu and Cao (2015) pointed out that universities should increase the current funding, improve student training programs and create an innovative management system so as to ensure the healthy and stable development of foreign student education ( $\mathrm{Li}, 2012$; Xi, 2013; Yu \& Cao, 2015); on the topic of acculturation and social adjustment of foreign students, research by Glass (2014) showed that there was no association between acculturation and social adjustment, acculturation was found to have a significant inverse relationship with leisure constraints, and the 
two most significant predictors of social adjustment were on-campus socialization opportunities and the establishment of strong host networks (Glass, 2014); Moreover, Buzoianu, Popescu, Bob, and Suciu (2015) pointed out that social support was an important factor associated with the degree of culture shock and should be taken into consideration in order to protect against or help to overcome psychological distress experienced by foreign students (Buzoianu et al., 2015). The previous researches mostly focused on theoretical study at the macro level, empirical study at the micro level was not very adequate, and most of the objects of studies were foreign students' education of some countries, and the study of regional foreign students education was relatively scarce.

At present, the foreign students' education of China stays at a high speed development stage, governments from the central and local have attached great importance to foreign students education, in order to energetically develop it, a series of polices and plans are being formulated. Therefore, this paper will choose the Shandong province which is an educationally powerful province in China as the object of study, discuss the current situation and problems about the education scale of foreign students, international curriculum system setting, and the management of foreign students in this province based on the process of higher education internationalization, then provide some referential countermeasures and suggestions.

The following research methods were used: literature research method, to have a comprehensive understanding of the ancient and modern research work of foreign students education and further clear the research direction through reviewing relevant literature; text analysis method, selecting the relevant policy documents of the government, colleges and universities in Shandong province as object of analysis to grasp the current situation of the development of foreign students education in depth; data analysis method, collecting more data, processing and analyzing the data in order to state the development scale and describe the current development trend of international Students in Shandong province more effectively.

\section{The Current Situation of Foreign Students Education in Shandong Province}

\subsection{Sustained Expanding of Scale}

The foreign students education is an important channel to attract and cultivate international talents, China has attached great importance to it and issued a series of principles and policies in succession, such as "The Medium and Long-Term Reform and Development of Education Plan of China (2010-2020)" and "Study in China Plan", which have greatly promoted the development of foreign students education. The Shandong province energetically responded to the relevant calls, and vigorously strengthened the foreign students education, in the policy document of "The Medium and Long-Term Reform and Development of Education Plan of Shandong Province (2010-2020)", it pointed out that the number of foreign student population in Shandong would realize the goal of 30,000 by 2020 . And recently, the number was in the top throughout all the provinces of China. Statistics showed that, from the year of 2004 to 2014, the number of foreign students in Shandong dramatically increased fivefold from 3098 to 17896 (see Table 1). The annual growth rate fluctuated in a certain magnitude, but the general growth trend was stable, the annually average growth rate stayed at $20 \%$, and the number of foreign students would probably reach 28,000 by 2020 (see Figures 1 and 2).

Table 1. Statistics of foreign students in Shandong Province (2004-2014)

\begin{tabular}{lccccccccccc}
\hline Year & 2004 & 2005 & 2006 & 2007 & 2008 & 2009 & 2010 & 2011 & 2012 & 2013 & 2014 \\
\hline Number & 3098 & 5308 & 6754 & 8388 & 8944 & 9961 & 9938 & 11130 & 13770 & 14618 & 17896 \\
Growth Rate / \% & - & 71.3 & 27.2 & 24.2 & 6.6 & 11.4 & -0.2 & 12.0 & 23.7 & 6.2 & 22.4 \\
\hline
\end{tabular}

*Sources: The concise statistics of foreign students and internal resource. 


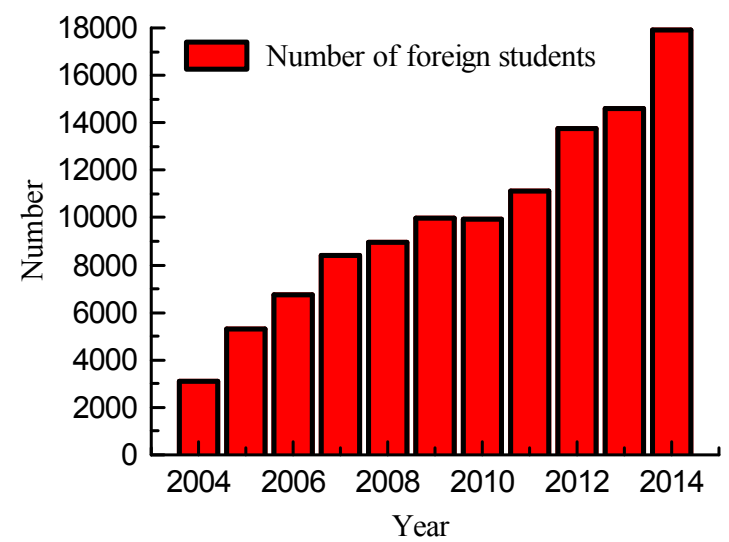

Figure 1. Histogram of the foreign students in Shandong province

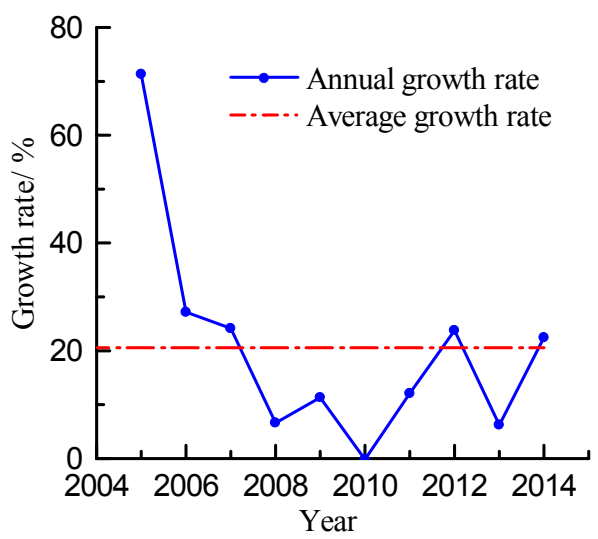

Figure 2. Growth rate of the foreign students in Shandong province

Meanwhile, in order to adapt to the new development situation, strengthen autonomy of the work of foreign students, the educational administrators and experts have drawn up the school-running indexes about which colleges and universities can accept foreign students, and the qualification evaluation is taken in provinces and cities. The number of qualified colleges and universities was 86 till 2012 in Shandong province, compared with 2004, the number had increased by 59, newly added some private universities, cadre schools and higher vocational colleges, such as Shandong Yingcai University, Shandong Management University and Shandong Technician Institute, etc. The increase in quantity and multi-layered and diversified of colleges and universities have greatly promoted the development of the scale of the foreign students education in Shandong.

\subsection{Constant Rising of the International Level of the Specialized Curriculum}

In recent years, along with the scale-up of foreign students in Shandong province, improving the level of foreign students and establishing a normative international specialized curriculum system have great effects on attracting excellent foreign resources and improving the quality of the foreign students education. To comply with the development trend of foreign students education, the colleges and universities in Shandong actively response to the national educational policy, enhance the exploitation of English or bilingual teaching curriculums relying on their own advantages, they have established a group of English teaching projects with international characteristics and achieved marked effects at present. Table 2 is about the English teaching programs for foreign students from 5 universities including Shandong University, Ocean University of China and China University of Petroleum (East China), etc. Among which the number of Shandong University's is the largest, 110 in total, and the second one is Shandong University of Science and Technology, 59 in total. The statistics analysis shows that the number of English teaching programs for doctoral students is the largest, 47.86 percent, the Master students' rank the second place, 43.16 percent, and the undergraduates' is the least, 8.98 percent, Which embodies the level of English teaching programs set for foreign students is variety, and the colleges and universities in Shandong province especially pay attention to the development of higher level of foreign student education. Furthermore, the contents of the programs really reflect internationalization features, we set an undergraduate program as example, Electrical Engineering and Automation (English teaching), whose curriculum system is set by the China University of Petroleum (East China), this program offers language, culture and situation, professional and experimental courses, which amounts to 2072 hours School courses and 27 weeks internship courses (see Table 3). The China University of Petroleum (East China) emphasizes on theory and practice in the course design, and offers Chinese courses to cater to foreign students' demand, in addition, the world frontier information of science and technology is mixed in course content, which makes foreign students better to know the subject frontier knowledge. 
Table 2. English teaching programs for foreign students in Shandong Province (including bilingual program)

\begin{tabular}{lccc}
\hline \multirow{2}{*}{ University } & \multicolumn{3}{c}{ Number } \\
\cline { 2 - 4 } & Undergraduate & Master & Doctor \\
\hline Shandong University & 2 & 42 & 66 \\
Ocean University of China & 1 & 5 & 27 \\
China University of Petroleum (East China) & 9 & 1 & 19 \\
Shandong University of Science and Technology & - & 39 & - \\
Jinan University & 9 & 14 & - \\
Statistics & 21 & 101 & 112 \\
Percentage /\% & 8.98 & 43.16 & 47.86 \\
\hline
\end{tabular}

*Sources: China Scholarship Council.

Table 3. Electrical engineering and automation specialty of China University of Petroleum

\begin{tabular}{|c|c|c|c|c|c|}
\hline \multicolumn{3}{|c|}{ Course Category } & \multirow[b]{2}{*}{$\begin{array}{l}\text { Elementary Chinese (including Chinese } \\
\text { Intensive Reading, Oral Chinese, Mediate } \\
\text { Chinese, Advanced Chinese) etc. }\end{array}$} & \multirow[t]{2}{*}{ Class Hour } & \multirow[t]{2}{*}{ Credit } \\
\hline \multirow{5}{*}{$\begin{array}{l}\text { Compulsory } \\
\text { course }\end{array}$} & \multirow{3}{*}{ Theory } & Language & & & \\
\hline & & $\begin{array}{l}\text { Culture and } \\
\text { Situation }\end{array}$ & Survey of China, Morality and Law, etc. & \multirow[t]{2}{*}{1992} & \multirow[t]{2}{*}{125} \\
\hline & & Professional & $\begin{array}{l}\text { Higher Mathematics, College Physics, } \\
\text { Renewable Energy Generation Technology, } \\
\text { Digital Power System Simulation and Analysis, } \\
\text { etc. }\end{array}$ & & \\
\hline & \multicolumn{2}{|c|}{ Experiment } & $\begin{array}{l}\text { Computer Application Technology, College } \\
\text { Physics Experiment, etc. }\end{array}$ & 80 & 4 \\
\hline & \multicolumn{2}{|l|}{ Practice } & $\begin{array}{l}\text { Metalworking Practice, Electrical Cognition } \\
\text { Practice, etc. }\end{array}$ & 27 Weeks & 27 \\
\hline
\end{tabular}

*Sources: Website of China University of Petroleum.

\subsection{Substantial Promotion of the Internationalization Degree of Faculty}

Teachers act as the constructors of curriculum system and executers of teaching, the internationalization degree of them have an important effect on promoting the construction of internationalization courses for foreign students, ensuring the quality of teaching, and strengthening the core competence of universities, etc. Colleges and universities in Shandong province, on the one hand, have brought in numerous overseas high-level talents to strengthen the construction of teaching staff according to their actual circumstance. On the other hand, they have paid more attention to increase the teachers' internationalization level and taken the way such as sending teachers to go abroad to improve the level of teachers in foreign language teaching and research. For example, the China University of Petroleum (East China) actively expanded channels, it engaged more than 20 foreign experts from other countries and regions to work there and 8 foreign professors for teaching and research work in 2013. At the same year, the supporting funds are raised from multi channels, more than 3 million yuan were mainly used to retain foreign experts, improve the international academic exchange fund and support core programs. Furthermore, most of the teachers who work for foreign students in Shandong University have the experience of study abroad. The university also has retained long-term experts and set up the flow stations of overseas experts to help relevant professional teachers to acquire teaching skills, grasp the course contents, draw lessons from useful experience and promote the construction of the university curriculum. The exchange and cooperation of teachers is really helpful to create the internationalized learning environment and help teachers to master the dynamic of international frontier research, improve academic level and enrich their teaching experience. The statistical results showed that there were 20773 faculties who participated in international cooperation and 
research from colleges and universities in Shandong province from the year 2007 to 2014, 11284 of whom were dispatched, and 9489 faculties were accepted. The percentage of dispatched and accepted faculties increased substantially over the years, the increasing range of dispatched ones was greater than that of the accepted ones (as shown in Figure 3), which further explained that the colleges and universities in Shandong province not only paid attention to fostering the internationalization level of teachers, but also emphasized on the output and transmission of native culture.

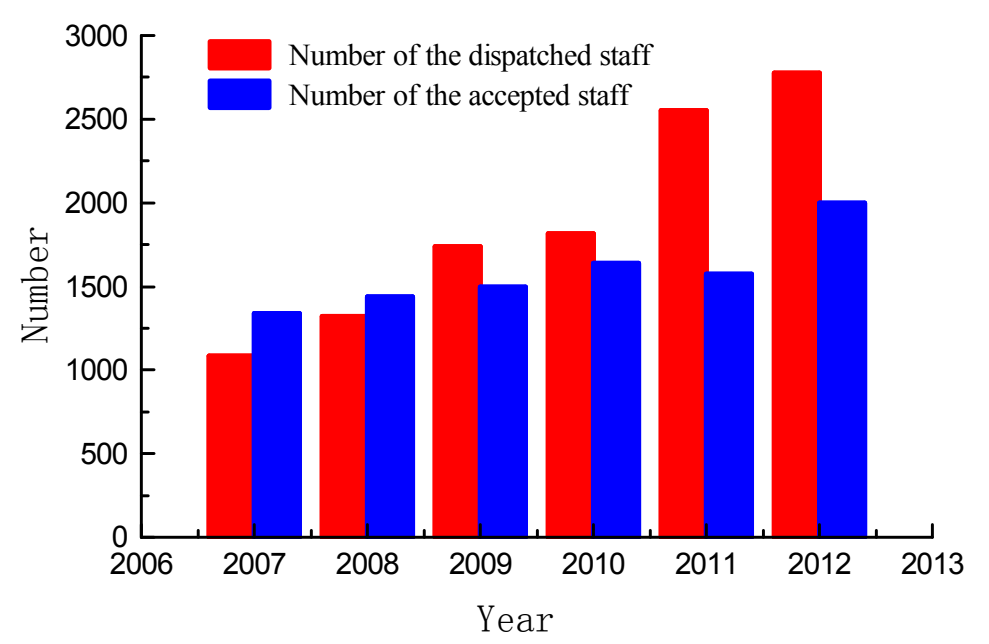

Figure 3. Histogram of dispatched and accepted staffs of universities in Shandong province

\subsection{Maturing of the Management}

The management of foreign students guarantees the smooth development of the foreign students education. After continuous explorations and reforms, the management of foreign students in Shandong province has been developed from experienced management towards scientific management and become more standard and painstaking, thereby creating a good learning, living and service environment for foreign students. On the one hand, basing on the full implementation of the policy "Enlarge the Scale, Improve the Level, Guarantee the Quality, and Normalize the Management" and the regulation "University Management Rule of Accepting Foreign Students", the colleges and universities in Shandong province actively establish the management system of foreign students, draw out related laws, and constantly explore the management methods that are suitable for the actual situations. For instance, in terms of the management system and the prevention mechanism of emergencies, the China University of Petroleum ((East China) has made rules and regulations, such as "Provisional Management Regulation of Accepting Foreign Students in China University of Petroleum (East China)", "Provisional Regulation of Foreign Students Enrollment Management in China University of Petroleum (East China)", and "Routine Management Regulation of Foreign Students", etc. Besides, this university has established some systems, such as the head teacher system of foreign students, the comprehensive quality assessment system, as well as the foreign student interview system. On the other hand, the management mode of foreign students education in Shandong province turned from closed management to collaborative management by government and universities. The college-based or administrative management mode is commonly used at present. Most of the universities such as the China University of Petroleum (East China), Shandong Normal University and Shandong University of Technology are using the college-based management mode, which gathers the routine management of foreign students, teaching and logistical services through establishing a secondary college as the management body. Among those universities, the college of international education in China University of Petroleum (East China) has developed into an integrated institution which gathered foreign student education, Chinese-foreign cooperation in running schools and international promotion of Chinese language since 2012, and under the secondary college, there has set up some teaching and research institutions, such as the international education department of Chinese and international education laboratory. Besides, the institutions have been equipped with professional teachers having profound academic background to cultivate talents. The administrative management mode separates government affairs and teaching affairs, which is helpful to strengthen the relationship among the departments in universities and lighten the burdens of the staffs who work in foreign students department. This mode is suitable for the university whose scale of foreign students is 
large. For example, the Ocean University of China is the one whose administrative management mode is so typical. In the Foreign Students Center of this university, there has set up the foreign students enrollment department, management department and offices. The work of those departments is to manage the school rolls and archives of foreign students and issue certificates of achievement, etc. To teach is carried on by each college, and convergence teaching model is implemented in this university, all the foreign students are arranged to study together with our native students.

\section{The Existing Problems in the Foreign Students Education}

With the changes in the global situation and the improvement of the level of higher education, today's foreign students' education in colleges and universities has a new context that can bring not only opportunities but also challenges. Though the foreign students education has been developing vigorously and the internationalization level of higher education has been improving continuously in Shandong province under the new global circumstance, the development of its foreign students education is still facing large predicaments and bottlenecks which seriously constraint and impact the introduction of international talents and the improvement of international education level of colleges and universities. The existing problems in foreign students education in Shandong Province are mainly reflected in the following three aspects.

\subsection{Uneven Distribution and Low Levels}

The statistical results showed that the foreign students of Shandong province were mainly centralized in the economic developed regions, such as Qingdao city, Yantai city, and Jinan city etc. Taking the top 10 universities in Shandong province in 2012 as examples, the reference standard was the numbers of foreign student's population (see Table 4).

Table 4. Ranking of foreign students of universities in Shandong Province

\begin{tabular}{|c|c|c|c|c|c|c|c|}
\hline Ranking & University & Location & $\begin{array}{c}\text { Total } \\
\text { Number }\end{array}$ & Ranking & University & Location & $\begin{array}{c}\text { Total } \\
\text { Number }\end{array}$ \\
\hline 1 & $\begin{array}{l}\text { Shandong } \\
\text { University }\end{array}$ & $\begin{array}{l}\text { Jinan, } \\
\text { Weihai }\end{array}$ & 3916 & 6 & $\begin{array}{l}\text { Weifang Medical } \\
\text { University }\end{array}$ & Weifang & 687 \\
\hline 2 & $\begin{array}{c}\text { Ocean University of } \\
\text { China }\end{array}$ & Qingdao & 1346 & 7 & $\begin{array}{c}\text { Taishan Medical } \\
\text { University }\end{array}$ & Taian & 631 \\
\hline 3 & Qingdao University & Qingdao & 1236 & 8 & $\begin{array}{c}\text { Shandong University of } \\
\text { Technology }\end{array}$ & Zibo & 541 \\
\hline 4 & Yantai University & Yaitai & 1070 & 9 & $\begin{array}{c}\text { China University of } \\
\text { Petroleum (East China) }\end{array}$ & Qingdao & 505 \\
\hline 5 & LuDong University & Yantai & 737 & 10 & $\begin{array}{l}\text { Shandong University of } \\
\text { Science and Technology }\end{array}$ & Qingdao & 407 \\
\hline
\end{tabular}

From Table 4, we know that the foreign students of Shandong province were mainly centralized in such universities, like Shandong University, the Ocean University of China and Qingdao University, etc. The concentration regions mainly were Jinan and Qingdao (the number of foreign students accepted by universities in Jinan was about 4,000 every year, while Qingdao was about 3,000). According to the statistics, the number of non-degree students accounted for more than $60 \%$ of all the foreign students in recent years (though the non-degree students accounted for $56.4 \%$, while the degree students accounted for $43.6 \%$ in 2014 , the non-degree students still dominated), most of the non-degree students were Chinese language students, scholars and Chinese culture amateurs. For example, the number of foreign students accepted by Shandong University was 655 in 2014, which included about 250 undergraduates, postgraduates and doctoral students, 330 language students and 75 international exchange students (Hu, 2014), the non-degree students accounted for $61 \%$ of the foreign students in total.

\subsection{Problems in Curriculum System}

In terms of the specialty structure, the science and engineering specialty of Shandong universities and colleges was weak, which caused the engineering foreign students less. Recently, the Chinese language and management economics had been hot specialties for the international guest students, for example, in 2014, the Chinese language trainees accounted for $50 \%$ of the total number of foreign students in Shandong University. The foreign 
students' professional choice tendency to liberal arts was not conducive to have more international exchange in the high-tech sector for the universities and colleges in Shandong, and it also influenced the specialty of foreign students education to develop in depth. In terms of the curriculum arrangement, the English teaching programs that offered for the foreign students mainly centralized at the postgraduate level, while less for the graduates, which cannot meet the demand of foreign students. Furthermore, in order to make the teaching management more convenient, some universities did not advocate foreign students to take elective courses from cross-specialty and inter-disciplinary, which hit the foreign students' learning interest at a certain extent. For instance, the three-year curriculum system of mechanical engineering offered 7 compulsory courses and 8 elective courses for foreign students in Shandong University, the elective course category and its degree of freedom for foreign students were limited in Shandong universities and colleges. Secondly, as restricted by teachers' English proficiency and teaching equipment, most of the universities in Shandong mainly use Chinese to teach foreign students, which is unfavorable for the foreign students to understand and learn the course contents in some degree.

\subsection{Problems in Management of Foreign Students}

It has been universities' consensus on the management of foreign students to follow the principle of "the intramural management will be in campus, the social management will be socialized", realize the integration of campus and social management and make it works towards legalization. With the continuous improvement of the level of economic and the quality of higher education, and the sustained expanding of the scale of foreign students in Shandong province, the problems of foreign students administration are increasingly complex. Firstly, the existing relevant laws and regulations were lack of a clear social management body, while the foreign students management work was always involved in foreign affairs and public security department, which made the universities hamper a lot in foreign students administration and many problems cannot be solved at a lower level, such as the problem of foreign students work-study or lodging outside etc. Secondly, the college-based management mode distinguishing the study and daily life of foreign students from Chinese students was used by most of the universities in Shandong, which hindered foreign students' acculturation at a certain extent. Thirdly, there are also problems of low efficiency and lack of service awareness in the foreign students administration. Some universities were lack of perfect long-term consultation projects and information service systems for foreign students, which resulted in the delaying in problem solving.

\section{Conclusion}

After the above research and analysis of the development of foreign students education in Shandong province, we can conclude that the government, universities and colleges in Shandong province have adopted a series of policies and measures to develop the foreign students education, and have obtained many achievements, which greatly pushed the process of internationalization of higher education. But in general, there is still much to be improved, such as the level and structure of foreign students, curriculum and management system for foreign students, etc. In order to develop the foreign students education and fully enhance the international competitiveness of higher education in Shandong province, we need to constantly improve and refine the work for foreign students education, and gradually expand the foreign students education market, establish a good brand of "studying in Shandong", the specific countermeasures are as follows.

\subsection{Enlarge the Scale and Improve the Foreign Students Structure}

\subsubsection{Increase Investment, Enhance the Competitiveness of Universities}

Firstly, establish and improve the diversification scholarship system that variously input by government, colleges and universities, the society and multinational companies, etc. increase funding for foreign students (Jiang, 2012). The government scholarship could be focused on high-level talents, while other scholarships are appropriately tilted to non-degree students to attract overseas excellent sources and improve the level of foreign students. Currently, the non-degree students account for a large proportion, to increase capital investment for those students is helpful to enlarge foreign students scale, and possibly helps to develop them into degree students possibly, which can improve the foreign students structure. Secondly, as an important part of foreign students' education, the private universities and higher vocational colleges play an important role in pushing the internationalization of higher education in Shandong province. The private universities and higher vocational colleges that suffice to accept foreign students should constantly improve their teaching facilities and strengthen their comprehensive power. In terms of the institutions, they can set up professional university foundation to expand foreign exchange and cooperation projects, and build education brand combining with their own characteristics, such as joining professional skills or some practical knowledge related to work-planning in courses. 


\subsubsection{Raise the Reputation of the Universities}

To enlarge the scale of foreign students in Shandong province, the institutes of higher education should pay attention to external transverse expansion and internal excavation in depth. On the one hand, Shandong government should encourage and support universities to run schools abroad, develop international education service projects, and improve the international influence of universities. The related education department can spread Shandong educational idea on its portal website, and introduce the characteristics of Shandong universities. The colleges and universities can expand overseas markets through such ways, like participating in overseas education exhibition, undertaking Chinese and foreign exchange forums and establishing online education platform, etc. On the other hand, with the continuously enhancement of economic strength in Shandong province, the foreign investment and cooperative enterprises have increased substantially, many multinational companies have large demand for professionals of Chinese language. The universities in Shandong province need to seize the opportunity basing on the level of educational services trade and build connection with foreign affairs service center where foreign chambers of commerce and foreigners relatively centralize, thereby offering language training service for foreign enterprises or individuals and developing the market of language learning groups.

\subsection{Perfect the Specialized Curriculums, Improve the Educational Quality}

\subsubsection{Optimize Specialty Structure, Diversify the Course Contents and Forms}

Firstly, the universities in Shandong province should base on the reality, combine with their own discipline advantage and specialty characteristics to strengthen the characteristic specialty construction. Secondly, the internationalization of curriculum content is the most dominant and direct form that can reflect the internationalization of foreign students education. The colleges and universities should carry out international comparative study in science and engineering majors, make actual plans and measures of the internationalization of specialties by taking advantage of the newest achievement of contemporary science and technology and push the arrangement of specialties and curriculums to be identical with the international standard. Thirdly, it's necessary to diversify the curriculum, appropriately increase elective courses and implement elastic credit system. At last, universities and colleges can set up short-term courses as supplementation of formal higher education courses for foreign students. For example, Shandong University offered some tailored curriculums according to foreign universities' need, which not only made full use of university resources, but also explored new paradigm of cooperation in education field.

\subsubsection{Build up Curriculums Taught in English, Improve Teaching Quality}

To promote the curriculum construction of teaching In English, firstly, the government administration departments and universities can set up special funds to design and explore curriculums, organize a special group and establish English teaching websites, etc. Secondly, colleges and universities should take measures to improve teachers' English level and teaching ability. The teachers' language proficiency and class control ability can be improved through such ways, like government-funded overseas study or refresher, teachers exchange, and classes showed together by the native and foreign teachers, etc. At last, constructing the textbooks in English for foreign students, improve the English teaching quality. The colleges and universities should eliminate obsolete materials timely, actively import foreign original textbooks which reflect the newest research achievements and development trend, and encourage the core teachers to participate in the work of English materials design and improve the effect of English teaching basing on their summarization of English teaching experience and combining with the local and the universities' practical situations.

\subsection{Reform and Improve the Administration System}

\subsubsection{Adhere to "Human-Centered" Principles, Strengthen the Service Awareness}

As foreign students' identities are special, their culture backgrounds and concepts of life are different from the native students', which demands the managers have inclusiveness, respect the culture differences and adhere to "human-centered idea" when they are in work and communicating with or serving for foreign students. Meanwhile, the colleges and universities should aggrandize propaganda of the native culture for foreign students, make foreign students know the local conditions and customs of Shandong province, be familiar with the college campus culture and the related management rules, and enhance the comprehensive and communicative ability of each other. In addition, paying attention to the difference of individuals and giving more humanistic care is of great importance. The colleges and universities should make detailed management for foreign students combing with individual characteristics, and they can solve the problem of acculturation of foreign students and perfect administration work through the ways such as psychological consultation, holiday tours and convening education 
working conference etc.

4.3.2 Define the Relationships between Responsibility and Authority, Increase Working Efficiency

With the growing scale of foreign students, the foreign students' extramural activities are relatively increasing, such as off-campus housing and travel outside etc. To effectively prevent and deal with the emergencies and new situations that will happen in the administration of foreign students off-campus, the provincial government and universities can connect with more management basing on the conclusion of their previous managerial experience, and diversify the management body. The social management departments and universities should be in coordination with each other according to laws, and work independently but manage together. The universities management departments should draw out detailed management rules and regulations for foreign students, and they can improve the quality of management staff and implement efficient management and services through training and evaluation.

\section{References}

Buzoianu, A., Popescu, C. A., Bob, M. H., \& Suciu, S. M. (2015). Culture shock, social support and mental health problems in foreign medical students in Romania. European Psychiatry, 30(1), 28-31. http://dx.doi.org/10.1016/S0924-9338(15)31481-4

Glass, C. R. (2014). International student adjustment to college: Social networks, acculturation, and leisure. Journal of Park and Recreation Administration, 32(1), 7-25.

$\mathrm{Hu}$, S. (2014). International Students Enrollment in 2014. Retrieved from http://www.view.sdu.edu.cn/new/2014/0907/65954.html

Jiang, K. (2012). The bottleneck problems and measures of international students education. Education Science of University, 2, 21-25.

Li, T. (2012). Reflections on the development of foreign student education in China. China Higher Education Research, 9, 27-29.

Roga, R., Lapina, I.,\& Müürsepp, P. (2015). Internationalization of higher education: Analysis of factors influencing foreign students' choice of higher education institution. Procedia-Social and Behavioral Sciences, 213, 925-930. http://dx.doi.org/10.1016/j.sbspro.2015.11.506

Shu, J. (2012). On the dominant status of American educational market for foreign students since 1980s. International Education Studies, 5(1), 148-153. http://dx.doi.org/10.5539/ies.v5n1p147

Xi, Y. (2015). The past, present and future of foreign students education in Chinese specialty of Peking University. China University Teaching, 9, 33-39, 42.

Yu, W., \& Cao, Y. (2015). Educational needs and experience analytics of foreign students education in China under the international educational background-An empirical study based on eight colleges in Shanghai. Education Exploration, 3, 90-95.

\section{Copyrights}

Copyright for this article is retained by the author(s), with first publication rights granted to the journal.

This is an open-access article distributed under the terms and conditions of the Creative Commons Attribution license (http://creativecommons.org/licenses/by/4.0/). 